\title{
INTEROPERABILIDADE NO PROCESSO DE PRODUÇÃO DE EDIFICAÇÃO COM GEOMETRIA NÃO CONVENCIONAL ${ }^{1}$
}

\author{
INTEROPERABILITY IN THE PRODUCTION PROCESS OF A NON- \\ CONVENTIONAL STRUCTURE
}

\author{
Eduardo Hernandes Domingues \\ Faculdade de Arquitetura e Urbanismo, USP \\ eduhdom@gmail.com \\ Claudia de Andrade Oliveira \\ Faculdade de Arquitetura e Urbanismo, USP \\ ctao@usp.br
}

\begin{abstract}
Resumo
O objetivo é apresentar o processo de produção de uma estrutura com geometria não convencional, baseado na interoperabilidade de recursos digitais para o projeto e fabricação dos elementos, bem como na interoperabilidade cultural que promove o trabalho integrado entre os agentes do processo. Os principais desafios do processo estão associados às especificidades programáticas, somadas ao prazo de construção de 120 dias. Trata-se da produção de um viveiro de borboletas dedicado à exposição interativa com objetivos didáticos e aberta ao público. A implantação em área interna de edificação tombada exigiu cuidadosa intervenção no espaço. A cúpula geodésica tem $13,75 \mathrm{~m}$ de diâmetro, $10,60 \mathrm{~m}$ de altura, é composta por 145 elementos de geometria triangular conformados em chapa de aço dobrada. Com superfície de $561 \mathrm{~m}^{2}$ e $5,93 \mathrm{~kg} / \mathrm{m}^{2}$, a estrutura tem volume útil de $1.056 \mathrm{~m}^{3}$. O sistema de vedação foi projetado para viabilizar a visitação pública e atividades de manutenção do viveiro. A apresentação do processo compreende princípios do projeto estrutural, requisitos funcionais e estéticos, método de montagem, fabricação e controle da qualidade dos elementos. A interoperabilidade permitiu a construção do objeto no prazo estabelecido. Não foi necessária a produção de protótipos físicos para validação das soluções de projeto.
\end{abstract}

Palavras-chave: Interoperabilidade. Produção digital. Cúpula geodésica.

\begin{abstract}
This paper aims to present a production process of a non-conventional structure, based on the interoperability of digital modelling tools focused on design and fabrication of building components, as well as the cultural interoperability that promotes the integrated work among stakeholders. The major challenges are related to the architectural programming and to the relatively short period of time (120 days) set out for completion of the construction works. It deals with the construction of a butterfly vivarium, oriented to educational purposes and accessible to public in general. Besides, the location area is inside a listed building demanding careful intervention in space. A geodesic structure was designed measuring $13.75 \mathrm{~m}$ in diameter, $10.60 \mathrm{~m}$ in height and consisting of 145 triangular shaped components, made from cold-formed sheet steel members. The surface area, surface mass and enclosed volume are, respectively, $561 \mathrm{~m}^{2}, 5.93 \mathrm{~kg} / \mathrm{m}^{2}, 1,056 \mathrm{~m}^{3}$. Cladding was designed to enable the public access and appropriate conditions for maintenance. The process comprises: principles of structural design, functional and aesthetic requirements, assembly method, manufacturing and quality control of components. The interoperability allowed the completion of the construction works on schedule. There was no need of physical prototypes for validation of the design solutions.
\end{abstract}

\footnotetext{
${ }^{1}$ DOMINGUES, Eduardo H.; OLIVEIRA, Claudia de A. Interoperabilidade no processo de produção de edificação com geometria não convencional. In: ENCONTRO BRASILEIRO DE TECNOLOGIA DE INFORMAÇÃO E COMUNICAÇÃO NA CONSTRUÇÃO, 7., 2015, Recife. Anais... Porto Alegre: ANTAC, 2015.
} 
Keywords: Interoperability. Digital production. Geodesic dome.

\section{INTRODUÇÃO}

O objetivo do artigo é apresentar o processo de produção de uma estrutura com geometria não convencional, baseado na interoperabilidade de recursos digitais para o projeto e para a fabricação dos elementos ${ }^{2}$, bem como na interoperabilidade cultural que promove o trabalho integrado entre os agentes do processo.

O desenvolvimento do trabalho é baseado em um estudo de caso singular: um viveiro de borboletas dedicado à exposição interativa com o público, instalado no Catavento Cultural e Educacional, sediado no Palácio das Indústrias. O local de implantação do viveiro é o claustro (pátio interno) do Palácio das Indústrias, um edifício tombado por órgãos de preservação do patrimônio histórico e cultural, situado na área central de São Paulo ${ }^{3}$.

Nesse contexto, o artigo explora as etapas de tomada de decisão: (a) quanto ao partido arquitetônico (estrutura espacial em forma de cúpula geodésica harmonizada com o edifício histórico) e (b) quanto aos recursos de interoperabilidade entre o software de manufatura e os softwares dos equipamentos de fabricação (equipados com controle numérico), e quanto à composição e integração da equipe, fatores que viabilizaram a consecução dos objetivos do projeto no prazo de 120 dias.

Os resultados, portanto, são focados na discussão de como o processo de produção permitiu o atendimento dos requisitos funcionais e estéticos da estrutura, bem como as limitações temporais, não fazendo parte deste trabalho a apresentação do dimensionamento estrutural da cúpula geodésica.

Na sequência são apresentados e analisados: no item 2 o escopo do projeto e o programa de uso, incluindo os princípios do projeto estrutural, requisitos funcionais, estéticos e de fabricação e montagem; no item 3 os principais atributos e especificidades do processo de projeto e de fabricação digital da estrutura de modo a atender a agilidade e precisão necessárias à montagem, bem como o prazo para a conclusão da obra; no item 4 os detalhes de projeto e de fabricação dos elementos decorrentes das melhorias possibilitadas pela interoperabilidade dos softwares de projeto e de fabricação digital. No item 5 são feitas as considerações finais sobre o trabalho.

\section{ESCOPO DO PROJETO E PROGRAMA DE USO}

O escopo de projeto do viveiro de borboletas - borboletário - para o Catavento Cultural e Educacional é o seguinte:

- Criação de um espaço confinado capaz de reproduzir condições ambientais que permitam aos visitantes a observação nas várias etapas do ciclo de vida das borboletas;

- Implantação em área interna de edifício tombado;

- Prazo proposto para projeto, aprovação, produção e montagem de 120 dias.

O projeto foi desenvolvido, considerando algumas das disciplinas arroladas no processo, com base nos requisitos e diretrizes apontados no Quadro 1.

A partir do entendimento do escopo, dos requisitos e das diretrizes adotadas no projeto, são

\footnotetext{
2 Projeto, modelagem e processo de produção e montagem de autoria do arquiteto Eduardo Hernandes Domingues.

${ }^{3}$ Catavento Cultural e Educacional. Mantido pela Secretaria de Cultura do Estado de São Paulo. Av. Mercúrio s/n. parque Dom Pedro II, Brás, São Paulo, SP.
} 
apresentadas nos subitens subsequentes as considerações sobre a geometria do viveiro, o revestimento e a sua implantação.

Quadro 1 - Condicionantes do projeto e produção da edificação

\begin{tabular}{|c|c|c|}
\hline Disciplina & Requisitos & $\begin{array}{l}\text { Diretrizes para as soluções de projeto e } \\
\text { produção }\end{array}$ \\
\hline \multirow[t]{2}{*}{ Arquitetura } & $\begin{array}{l}\text { Harmonia entre o } \\
\text { borboletário e edifício, de } \\
\text { acordo com princípios } \\
\text { essenciais das intervenções }\end{array}$ & $\begin{array}{l}\text { Volumetria compatível com as dimensões do } \\
\text { claustro, equilíbrio cromático e de formas } \\
\text { primando pela mínima intervenção, } \\
\text { distinguibilidade }\end{array}$ \\
\hline & Funcionalidade & $\begin{array}{l}\text { Controle dos acessos de modo a permitir a } \\
\text { entrada do público; atividades rotineiras de } \\
\text { manejo das borboletas e manutenção }\end{array}$ \\
\hline \multirow[t]{3}{*}{ Biologia } & \multirow{2}{*}{$\begin{array}{l}\text { Criação de um microclima } \\
\text { adequado à criação de } \\
\text { borboletas }\end{array}$} & $\begin{array}{l}\text { Espaço interno sem cantos ortogonais; } \\
\text { máximo volume interno com base na área de } \\
\text { projeção da edificação }\end{array}$ \\
\hline & & $\begin{array}{l}\text { Incorporação de árvores existentes no } \\
\text { interior do borboletário; espaços e suportes } \\
\text { para plantio de espécies vegetais } \\
\text { necessárias à composição do viveiro }\end{array}$ \\
\hline & $\begin{array}{l}\text { Controle da entrada de } \\
\text { radiação solar }\end{array}$ & $\begin{array}{l}\text { Máxima área de exposição ao sol com uso } \\
\text { de filtro de luz solar (tela de sombreamento) }\end{array}$ \\
\hline Paisagismo & $\begin{array}{l}\text { Preservação as árvores } \\
\text { existentes }\end{array}$ & $\begin{array}{l}\text { Locação do borboletário sem a necessidade } \\
\text { de transplante de árvores }\end{array}$ \\
\hline \multirow[t]{3}{*}{ Produção } & $\begin{array}{l}\text { Compatibilidade com todos } \\
\text { os processos de producão }\end{array}$ & Projeto paramétrico; prototipagem virtual \\
\hline & Prazo & Simulação de montagem e fabricação digital \\
\hline & $\begin{array}{l}\text { Implantação em local com } \\
\text { limitação de acesso de } \\
\text { equipamentos e elementos } \\
\text { de grande porte }\end{array}$ & $\begin{array}{l}\text { Processo de montagem por meio de } \\
\text { elementos transportáveis manualmente }\end{array}$ \\
\hline Manutenção & $\begin{array}{l}\text { Portabilidade do } \\
\text { revestimento }\end{array}$ & $\begin{array}{l}\text { Dissociação do revestimento dos elementos } \\
\text { estruturais; sistema de fixação da tela de } \\
\text { revestimento }\end{array}$ \\
\hline
\end{tabular}

Fonte: Autores.

\subsection{Geometria}

Entre as edificações são exemplos de geometria não convencional, ou complexa, as superfícies com dupla curvatura como, por exemplo, as cúpulas que proporcionam maior espaço interno, com o mínimo de superfície de cobertura e com pouca interferência de apoios internos. Com frequência as edificações que utilizam esse tipo de geometria são: (a) construídas por modelagem como, por exemplo, com o concreto armado; ou (b) construídas por adição de elementos de pequeno porte, como, por exemplo, os tijolos. Construções produzidas por esses processos não atendem a todas as demandas do programa deste projeto. A maior parte dessas superfícies é opaca e não produz o efeito de filtro solar, além disso, o tempo para a sua execução excede o prazo estipulado.

O processo construtivo que melhor atende às demandas do programa de necessidades é a construção de uma cúpula treliçada em aço. Uma treliça de estrutura metálica, montada com perfis laminados ou conformados, permite produzir uma grade com as características geométricas de superfícies com dupla curvatura. Essa mesma treliça de estrutura metálica, 
que utiliza perfis delgados, proporciona uma grande superfície para revestimento que pode ser configurada como filtro solar.

Há diversos tipos de cúpulas treliçadas, mas cinco delas são utilizadas na prática (MAKOWSKI, 1984 apud VENDRAME 1999): cúpulas nervuradas, cúpulas Schwedler, cúpulas com malha "three-way", cúpulas lamelares e as cúpulas geodésicas.

Dentre estes tipos, as cúpulas geodésicas apresentam algumas vantagens competitivas. A partir de 1945 Richard Buckminster Fuller, um filósofo, inventor e professor, dedicou-se ao estudo da trigonometria esférica e das formas geodésicas encontradas na natureza. Fuller não foi o inventor da geodésica ${ }^{4}$, mas foi ele quem popularizou o seu uso. É dele a autoria da geodésica conhecida como Biosfera instalada em Montreal para ser o pavilhão dos Estados Unidos na exposição de 1967. Um setor esférico com 76 m de diâmetro e $62 \mathrm{~m}$ de altura. Fuller acreditava que a massa de um edifício refletia a extensão do desenvolvimento da industrialização, bem como da humanidade (OTTO, 2005 apud EDEMSKAYA, 2014).

Nas geodésicas, como as criadas por Buckminster Fuller, a variação do comprimento das barras estruturais, calculadas matematicamente, é pequena e isso viabiliza a padronização e pré-fabricação desses elementos, resultando na simplificação da sua construção.

No Brasil, as cúpulas geodésicas são produzidas, comumente, com elementos tubulares cujas ligações (nó típico ${ }^{5}$ são, predominantemente, aqueles usados para estruturas espaciais planas. São ligações realizadas pela estampagem das extremidades das barras sobrepostas e conectadas por um único parafuso, não possibilitando um bom acabamento.

Foi necessário, portanto, o abandono das práticas de construção convencionais e adoção de princípios de projeto e montagem assemelhados aos da produção industrial mecânica, com objetivo de criar uma arquitetura diferenciada e que pudesse atender aos requisitos do programa. Afinal, a tecnologia, os materiais e a construção são fatores interdependentes que alteram a arquitetura, com afirma Edemskaya (2014, p. 9) ao analisar como os avanços nos meios de meios de produção influenciaram a prática de projeto e produção arquitetônica.

Portanto, o partido adotado como solução para atender ao programa foi uma cúpula geodésica, produzida com elementos construtivos de formato triangular (três tipos de triângulos isósceles), confeccionados em chapa de aço do dobrada. Essa solução permitiu que as ligações entre os elementos fossem aparafusadas e com bom acabamento.

A decisão por uma geodésica de frequência $3 v^{6}$ permitiu que os elementos que compõem a esfera tivessem dimensões compatíveis com os seis processos utilizados na produção: corte; conformação; solda; jateamento; galvanização e pintura eletrostática. Cada processo foi executado por um fornecedor diferente e as dimensões desses elementos não conflitaram com os recursos disponíveis. Todas as peças foram transportadas em VUCs ${ }^{7}$.

\footnotetext{
${ }^{4} \mathrm{O}$ primeiro domo geodésico em concreto na forma que se conhece atualmente foi construído em Jena, Alemanha em 1922. Walter Bauersfield, um cientista alemão, chefe de design da Zeiss, indústria ótica, o projetou para utilização como edifício. A cúpula tinha $25 \mathrm{~m}$ de vão com apenas $60,3 \mathrm{~mm}$ de espessura. Era uma casca em ferro cimento, cuja armação era uma geodésica. (LOTUFO; LOPES, 1981; VENDRAME, 1999)

${ }^{5}$ Sistema de ligação este denominado na EESC-USP como nó típico, projetado com poucos estudos e baseados em hipóteses simplistas (VENDRAME, 1999).

${ }^{6}$ Numa geodésica chama-se frequência o número de partes ou segmentos no qual as arestas do poliedro principal são subdivididas (LOTUFO; LOPES, 1981, p. 30). No caso foram utilizados três formatos de triângulos.

7 VUC: Veículo Urbano de Carga. Veículo de transporte que não tem restrições de acesso ao Centro Expandido da Cidade de São Paulo e pode circular a qualquer hora.
} 
Os elementos produzidos com chapa de aço ABNT $1020^{8}$ foram cortados e conformados por equipamentos equipados com controle numérico produzindo elementos idênticos aos projetados.

A massa por área é de $5,93 \mathrm{~kg} / \mathrm{m}^{2}$ enquanto coberturas espaciais com um único vão, comparáveis à estrutura em análise, têm, tipicamente, massa de 25 a $36 \mathrm{~kg} / \mathrm{m}^{2}$ (STEEL CONSTRUCTION INSTITUTE, 1997, p. 125). Estimativas feitas por Lotufo e Lopes (1981, p. 4) apontam que a cúpula denominada Biosfera, de Buckminster Fuller, foi construída com $600 \mathrm{t}$ de barras tubulares de aço o que resulta em, aproximadamente, $40 \mathrm{~kg} / \mathrm{m}^{2}$.

\subsection{Revestimento}

A equipe responsável pela implantação e manutenção do borboletário no Catavento Cultural e Educacional especificou o revestimento com tela de proteção agrícola com $30 \%$ de sombreamento ${ }^{9}$.

A tela de sombreamento agrícola é um material frágil e precisa ser substituída com frequência devido a: (a) eventuais danos ocasionados por pequenos acidentes, uma vez que a tela não resiste ao corte ou impacto; ou (b) durabilidade ao intemperismo (o fabricante garante o produto por 5 anos).

Para que a substituição de telas danificadas seja feita de forma a não prejudicar o funcionamento do borboletário, além de evitar a fuga de borboletas durante a manutenção, foi desenvolvido um sistema de instalação do revestimento em segmentos com as mesmas dimensões dos elementos triangulares; assim a cada um dos vãos corresponde um elemento de revestimento portátil.

Os elementos de revestimento portáteis, utilizados na manutenção, têm massa aproximada de $20 \mathrm{~kg}$ e dimensões que permitem o transporte por duas pessoas.

Cada segmento tem área aproximada de $2,5 \mathrm{~m}^{2}$ que equivale a $0,5 \%$ da área de revestimento. Um conjunto de elementos de revestimento suplementar permite que a manutenção seja feita por substituição de um segmento danificado por outro, igual, íntegro e previamente preparado.

Esses segmentos de revestimento são compostos de elementos ligados à estrutura por encaixe e fixados por seis porcas-borboleta. A operação de substituição pode ser feita em minutos por duas pessoas, sem uso de ferramentas.

\subsection{Implantação}

Por se tratar de uma intervenção em edifício tombado ${ }^{10}$, a implantação do borboletário exigiu cuidadosa análise e levantamentos precisos, por meio dos quais foram determinadas algumas características da estrutura e do seu processo de montagem.

Segundo os princípios essenciais das intervenções em edifícios e sítios históricos deve-se primar pela busca de soluções que atentem para a distinguibilidade da ação contemporânea a mínima intervenção "[...] que significa fazer aquilo que é necessário e suficiente (mínimo

\footnotetext{
${ }^{8}$ Segunda a norma ABNT NM 87:2000 a composição química (em percentagem) do aço ABNT 1020 é: Carbono entre 0,18 a 0,23\%; Manganês entre 0,30 a 0,60\%; Fósforo 0,04\% e Enxofre 0,050\% (ASSOCIAÇÃO BRASILEIRA DE NORMAS TÉCNICAS, 2000).

9 Tela de marca comercial Sombrite produzida pela empresa Equipesca Equipamentos de Pesca Ltda, estabelecida em Campinas - SP.

10 Tombado pelo Conselho de Defesa do Patrimônio Histórico, Arqueológico, Artístico e Turístico do Estado de São Paulo (CONDEPHAAT) em 1982 e pelo Conselho Municipal de Preservação do Patrimônio Histórico, Cultural e Ambiental da Cidade de São Paulo (CONPRESP) em 1991.
} 
não pode equivaler a insuficiente) [...]" (KÜHL, 2010). Por se tratar da inserção de uma nova estrutura em local não edificado, o edifício em si não seria afetado, porém o processo construtivo devia considerar as limitações e restrições impostas pelo edifício principal, que não podiam ser ultrapassadas ou resultar em desconfiguração da edificação tombada.

As instalações do Catavento Cultural e Educacional ocupam toda a área de uma edificação histórica - Palácio das Indústrias - no Parque Dom Pedro II, região central da cidade de São Paulo. O borboletário está implantado no centro do espaço chamado de claustro, um quadrilátero ajardinado medindo em planta $50 \mathrm{~m}$ por $50 \mathrm{~m}$, fechado numa face pelo volume principal do edifício e nas demais por três corredores cobertos. O claustro é uma das três partes em que se divide o edifício, "do ponto de vista da distribuição dos espaços no conjunto arquitetônico" (CARVALHO, 2009, p. 45).

O Palácio das Indústrias foi projetado pelo arquiteto Domiziano Rossi com a colaboração dos arquitetos Ramos de Azevedo e Ricardo Severo. O edifício, destinado a abrigar exposições agrícolas, industriais e comerciais, foi construído, em estilo eclético, por iniciativa da Secretaria de Agricultura, Comércio e Obras Públicas do Estado, entre 1911 e 1924. "Nessa área, em diversas exposições, foram expostos desde pequenos produtos [...] a automóveis" (CARVALHO, 2009, p. 47).

Após décadas sendo usado com pavilhão de exposições o Palácio, a partir da segunda metade do século XX, passou a abrigar diversos órgãos públicos de São Paulo (Estado e Município) sofrendo intervenções sem qualquer respeito à arquitetura original (CARVALHO, 2009, p. 52). Em 1990 teve início, sob a coordenação da arquiteta Lina Bo Bardi, o projeto para a nova sede da Prefeitura de São Paulo ${ }^{11}$, do qual fazia parte o restauro do Palácio das Indústrias. O Palácio abrigou a Prefeitura de 1992 até 2004. O Catavento Cultural e Educacional foi inaugurado em 2009, recuperado a função original do edifício: espaço para exposições.

A Figura 1 ilustra o local de implantação do borboletário no claustro. O acesso ao claustro a partir das áreas externas ao Palácio deve ser feito por meio de duas portas e escadas que inviabilizam a entrada de equipamentos de porte para o transporte e içamento de cargas, comuns na montagem de cúpulas geodésicas. A limitação de acesso é mais um critério que, em conjunto com as limitações dimensionais impostas pelos seis processos utilizados na produção (ver item 2.1), determinou o tamanho máximo dos elementos de montagem da geodésica.

O diâmetro adotado de 13,75 m tem uma relação de proporção de, aproximadamente, 1:4 entre a sua dimensão e a do claustro. Com altura de $10,60 \mathrm{~m}$, superfície de $561 \mathrm{~m}^{2}$ e composta por 145 elementos de geometria triangular, a cúpula resultou em um conjunto harmônico, em volumetria e proporções, com o entorno (Figura 2).

Ao entrar no claustro um visitante consegue ver a esfera toda num relance. A pequena construção existente no centro do claustro, que anteriormente era um poço, foi incorporada ao projeto e nela foi instalado o berçário das borboletas. O olhar atendo do visitante posicionado ao lado externo do viveiro possibilita a visualização do poço, no centro da geodésica (Figura 3). A implantação da geodésica e a permeabilidade visual da sua superfície não impedem a leitura do edifício.

\footnotetext{
11 O projeto para a nova sede da Prefeitura de São Paulo incluía, além do restauro do Palácio, construção de um novo edifício substituindo um dos viadutos no Parque Dom Pedro II. A transferência da Prefeitura para o Palácio restaurado foi concluída em 1992, mas a demolição do viaduto e a construção do novo edifício nunca se efetivaram. (Informação disponível em <http://www.institutobardi.com.br/linha tempo.asp>. Acessada em 25 de maio de 2015.
} 


\section{TIC2015}

Figura 1 - Vista aérea do edifício Palácio das Indústrias. O disco vermelho no centro do claustro indica o local de implantação do viveiro de borboletas

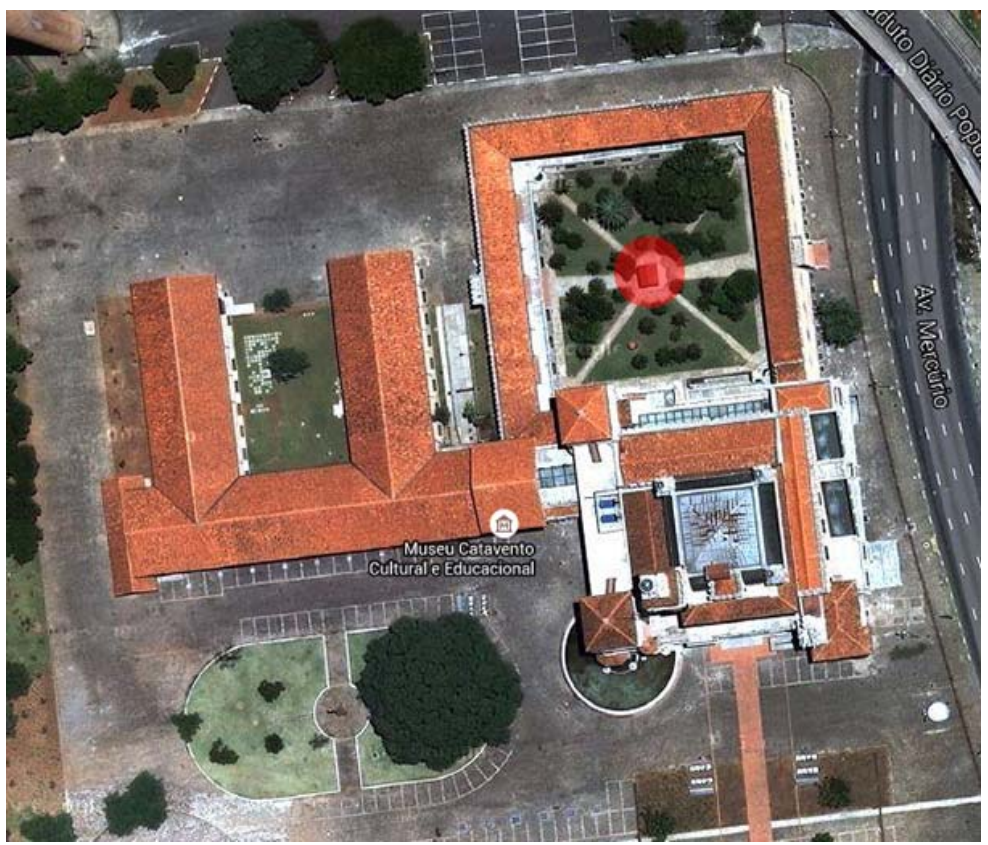

Fonte: Google Maps, 2015.

Figura 2 - Vista aérea do borboletário implantado no centro do claustro

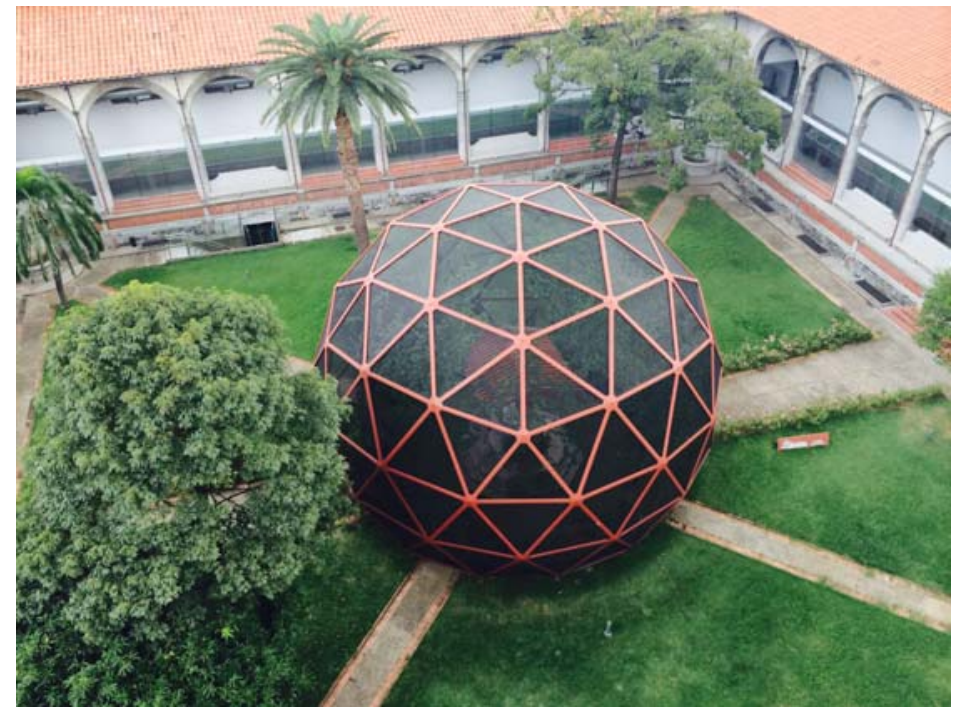

Fonte: Acervo pessoal dos autores, 2015.

O volume interno de $1.056 \mathrm{~m}^{3}$ resultou num espaço adequado à criação de borboletas, com o máximo aproveitamento volumétrico e a mínima área de intervenção em planta.

O cadastro do espaço físico, com localização exata das árvores, forneceu com segurança a informação de que as árvores estariam preservadas; algumas no espaço interno.

$O$ assentamento da geodésica no terreno foi projetado de modo ser o menos invasivo possível. Quando da necessidade de retirada da cúpula não haverá prejuízo para os elementos originais do claustro que foram preservadas, tais como o poço e os passeios. 
Figura 3 - Elevação do borboletário com o detalhe de um dos acessos (esquerda); visibilidade do poço no interior da geodésica (direita)

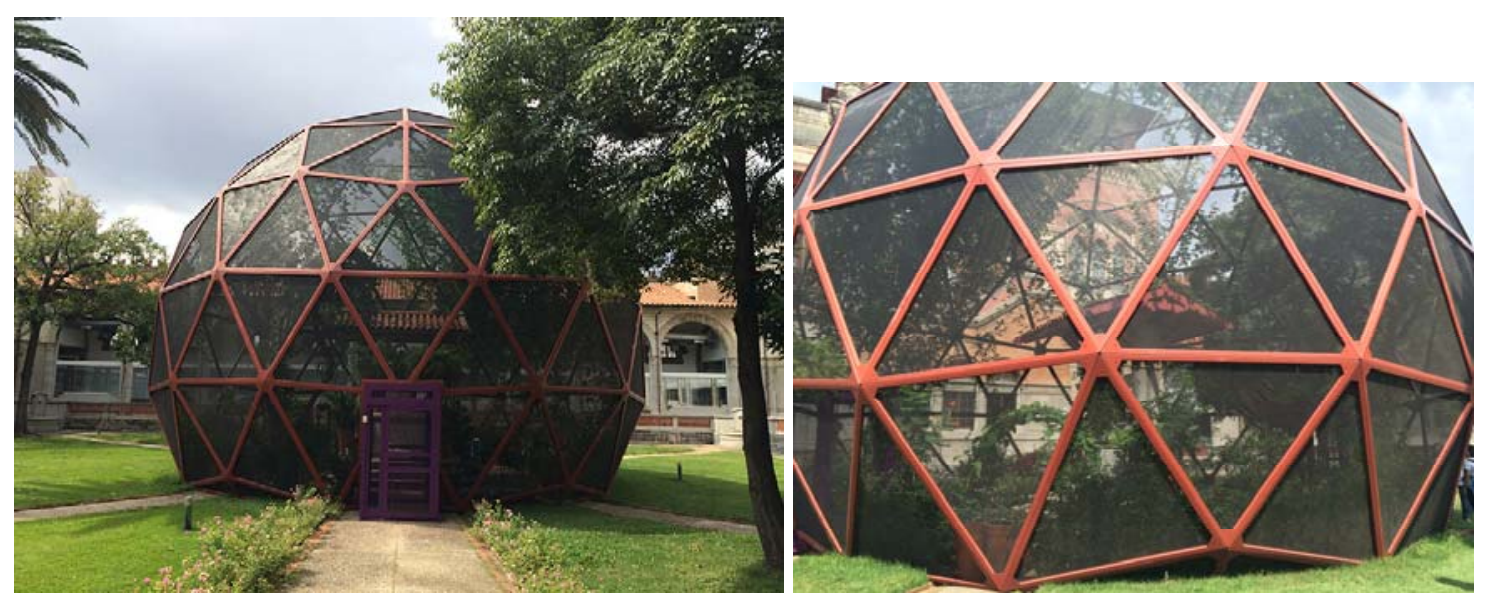

Fonte: Acervo pessoal dos autores, 2015.

\section{ATRIBUTOS DO PROCESSO DE PROJETO E FABRICAÇÃO DIGITAL}

Para construções com geometria não convencional - como o caso ora apresentado - para as quais não há elementos construtivos comercialmente disponíveis, a fidelidade da representação das ideias é o um dos pontos fulcrais do processo.

Os riscos de imprecisão e propagação de erros são minimizados quando a gênese do projeto é baseada em modelos digitais, no âmbito do conceito da Modelagem da Informação da Construção (BIM). O projeto deixa de ser composto por ilustrações pictóricas e é formado a partir de uma única base digital que oferece dados aos vários agentes do processo. Adicionalmente o processo de troca de dados é agilizado, garantindo a rastreabilidade e confiabilidade das informações.

A despeito da interoperabilidade tecnológica, que garante o intercâmbio de dados entre os aplicativos usados pelas várias equipes, o sucesso de uma empreitada não prescinde da interoperabilidade cultural que pode ser compreendida como a capacidade de gerenciar o fluxo de informações significativas e coordenar a interlocução entre os participantes no processo de projeto. Essa habilidade de gerenciar o trabalho colaborativo entre membros de equipes transdisciplinares é o que Young Jr et al (2007) também sugerem como sendo a interpretação da interoperabilidade sob uma perspectiva cultural. Essa abordagem cultural ganha significado se vista sob a perspectiva apontada por Bernstein e Pittman (2004) quando analisam as barreiras para a implantação do BIM. Aqueles autores apontam a necessidade de modificações na tradição cultural de projeto e construção, por meio da redefinição das responsabilidades dos participantes em um processo no qual os dados intercambiados e compartilhados entre as partes tornam-se, praticamente, indissociáveis.

Para tanto é necessária a qualificação dos membros da equipe quanto ao domínio tecnológico das técnicas de fabricação e montagem da estrutura, bem como a definição de protocolos de relacionamento entre as partes, garantindo uma visão sistêmica do processo.

No caso estudado a materialização dos princípios da interoperabilidade se deu a partir da formação de uma equipe coordenada pelo arquiteto autor do projeto, que também foi responsável pela modelagem dos elementos da cúpula e montagem da geodésica.

Outra ação importante foi a identificação dos atributos de um software de manufatura que pudesse favorecer, concomitantemente, o desenvolvimento do projeto de arquitetura e a modelagem e prototipagem digital, além de viabilizar a verificação do dimensionamento estrutural. Paralelamente, foram identificados no mercado local prestadores de serviço 
capazes de produzir elementos por meio de equipamentos operados por controle numérico computadorizado (equipamentos CNC), a partir dos arquivos (DXF) gerados pelo software de manufatura selecionado. A equipe de montagem da cúpula foi formada por cenotécnicos com formação multidisciplinar (marcenaria, serralheria, mecânica) e familiarizados com montagem de estruturas não convencionais.

O emprego do software de manufatura escolhido ${ }^{12}$ possibilitou a análise reversa do processo. Durante a fase de projeto puderam ser feitos exercícios de simulação digital da montagem. A análise precoce da montagem e das operações necessárias à manutenção da estrutura permitiu a adequação dos elementos de forma a facilitar tais operações.

A prototipagem digital ainda permitiu a inclusão ou alteração dos sistemas de ligação e fixação substituindo apoios simples por apoios com encaixes, tarefas de fixação com redução de operações ou ainda a eliminação de interferências geométricas que só seriam detectadas no momento da montagem.

\section{PROJETO E PRODUÇÃO}

Cabe ao projeto tirar o máximo proveito da interoperabilidade dos softwares. Recursos simples de recorte com ferramentas de alta precisão proporcionaram as seguintes melhorias:

- Identificação e codificação dos elementos para orientar e facilitar a montagem. O domo utiliza três formatos de triângulos que foram identificados com formas geométricas recortadas nos elementos. As Figuras 4 e 5 mostram as formas geométricas (pentágonos, quadrados e triângulos) usadas para identificação dos elementos;

- Código de posicionamento com o formato de recorte de quebra-cabeça (ver Figuras 4 e 5). Localizado no ponto onde os braços são ligados e fixados por solda TIG13, evitou: erros na montagem dos triângulos e o uso de dispositivos auxiliares de fabricação que assegurassem a precisão geométrica e dimensional da peça.

Figura 4 - Identificação e codificação no projeto dos elementos

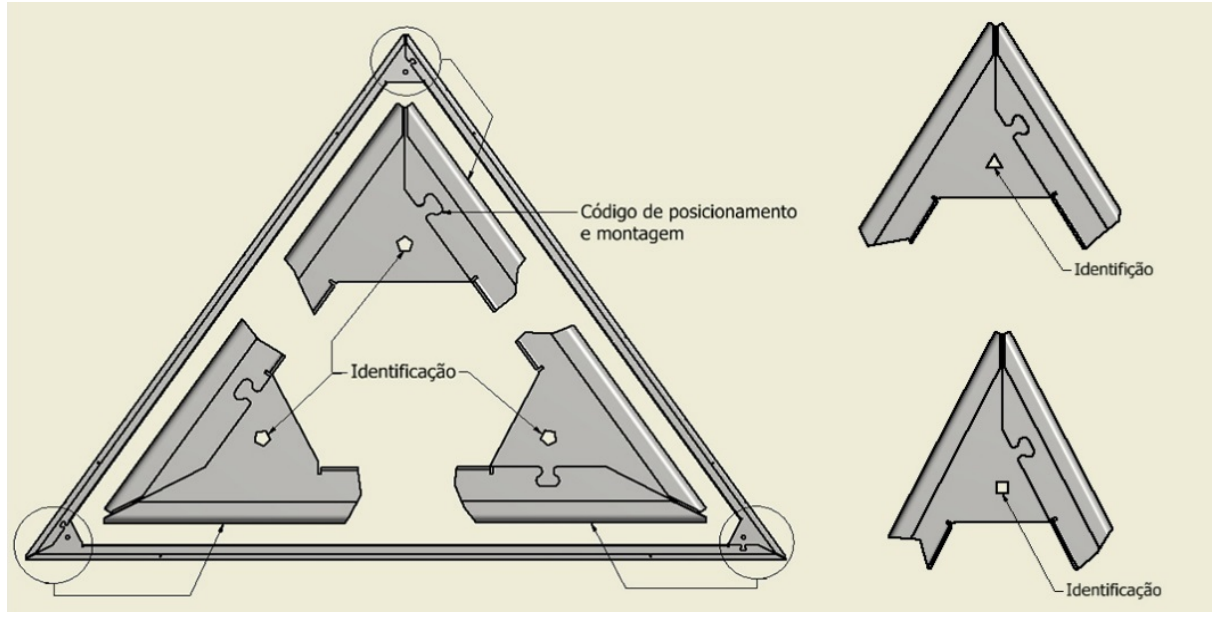

Fonte: Acervo pessoal dos autores, 2015.

\footnotetext{
12 Autodesk Inventor

13 TIG - Tungsten Inert Gas: processo de soldagem a arco elétrico entre um eletrodo não consumível de tungstênio e as peças a serem unidas, com ou sem deposição de material. Esse processo deixa a solda limpa, sem os resíduos provenientes da queima do revestimento dos eletrodos, sendo adequado para peças que receberão proteção anti-corrosão por processos eletrolíticos (ESCOLA SENAI SUIÇO BRASILEIRA, 2005)
} 


\section{N-}

Figura 5 - Detalhe da identificação e código de posicionamento na geodésica montada.

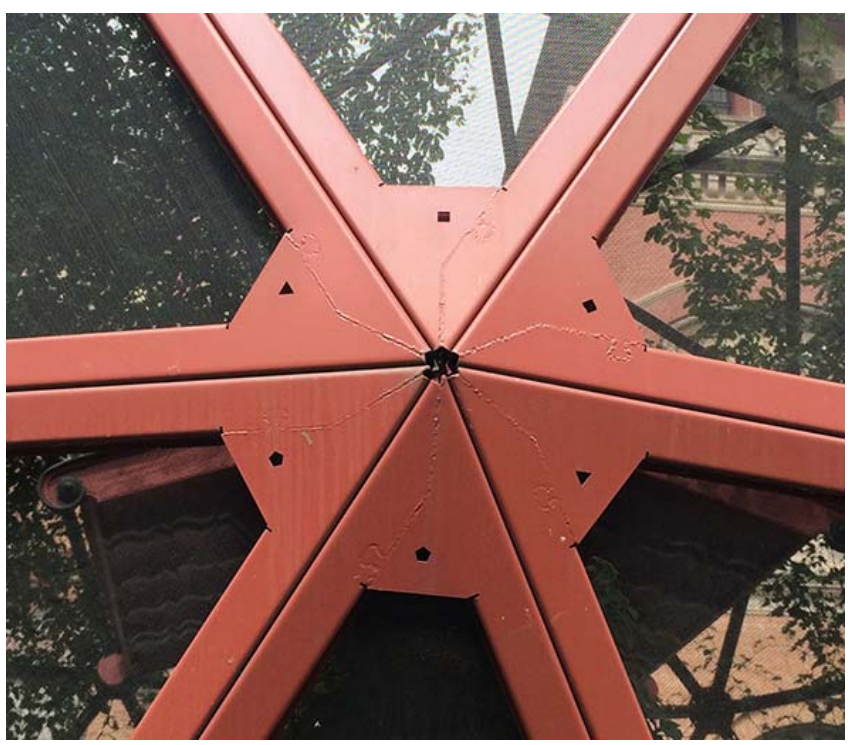

Fonte: Acervo pessoal dos autores, 2015.

O corte das peças foi feito por dois processos em máquinas CNC: (a) jato de água abrasivo para a fabricação dos braços dos triângulos; esse processo não cria as zonas afetadas pelo calor (HAZ Heat Affected Zones) e, portanto, não traz risco de alteração das propriedades do aço e (b) a laser para pequenos recortes (identificação e códigos de posicionamento) que, em razão da escala, não oferecem risco de superaquecimento da peça.

Após o corte das peças o próximo processo, a dobra das peças, também foi realizado por equipamento com controle numérico. Cada lado dos triângulos que será ligado aos triângulos vizinhos forma um diedro entre a face visível e a face ligada que varia em função de sua posição. Apesar da precisão do método, todas as peças só foram liberadas para o próximo processo após terem sido conferidas com dispositivos produzidos por corte a laser, identificados com o mesmo critério usado para a codificação dos elementos (ver Figura 6).

Para controlar a qualidade de montagem das peças, foi estabelecida uma paginação diferente dos furos para cada tipo de ligação entre dois triângulos, Figura 7.

O enrijecimento das ligações entre dois triângulos foi obtido por meio da paginação dos furos nessas ligações de forma que as fixações não ficassem alinhadas, como indicam as os detalhes da Figura 7 e as setas na Figura 8.

Figura 6 - Dispositivos de conferência de diedros
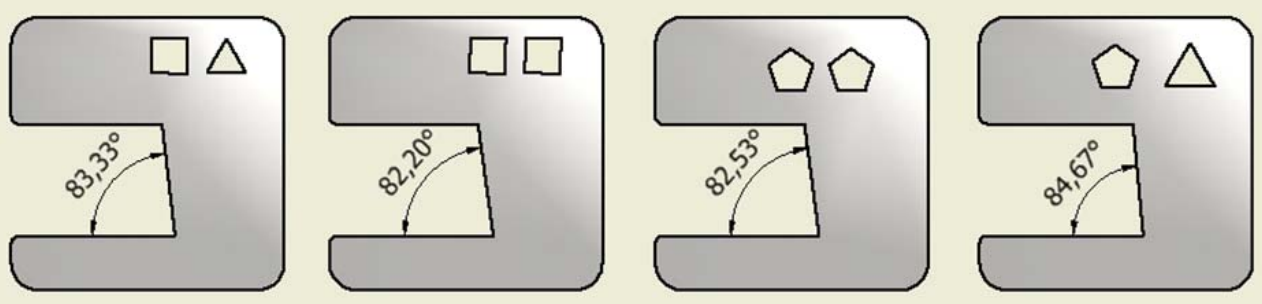

Fonte: Acervo pessoal dos autores, 2015. 
Figura 7 - Paginação específica dos furos para cada tipo de ligação entre triângulos

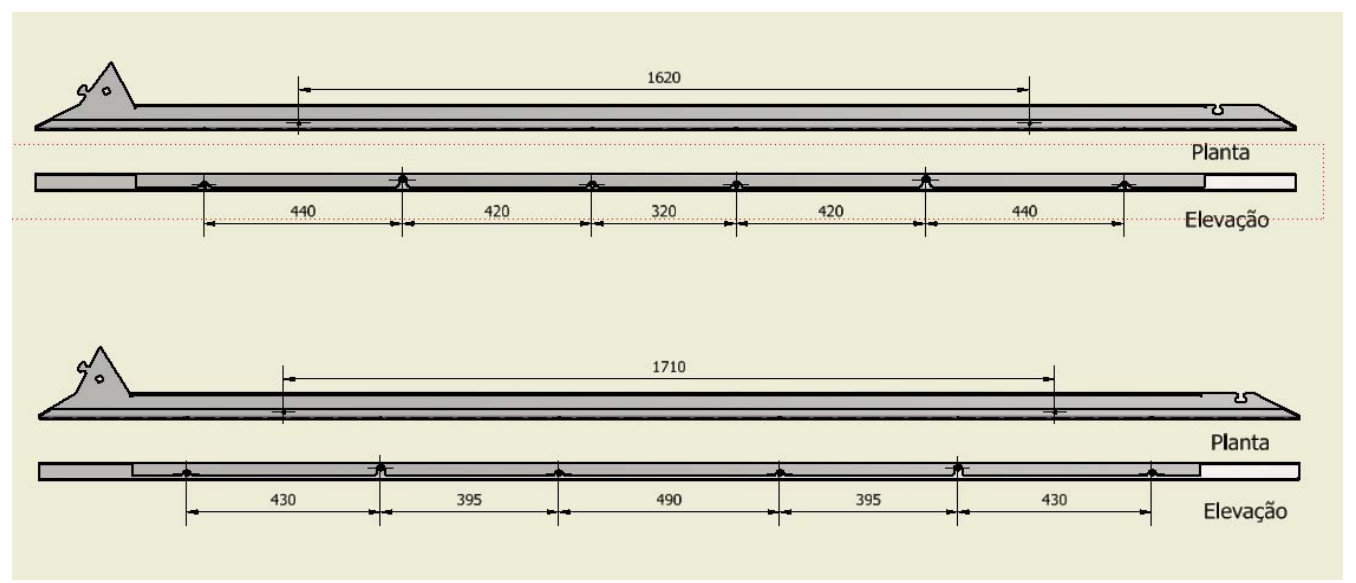

Fonte: Acervo pessoal dos autores, 2015.

O uso do software de manufatura permitiu que, na fase de projeto, fossem criados detalhes reproduzidos com fidelidade na fase de produção, os quais levaram a melhorias nas tarefas de produção, montagem e manutenção. $O$ acesso aos componentes de fixação nas ligações entre triângulos foi facilitado pelos recortes feitos na aba oposta (Figura 8). Ligar dois triângulos foi tarefa simples, mesmo com componentes alojados em local de difícil acesso.

Figura 8 - Recursos para enrijecer a estrutura e facilitar a fixação entre triângulos

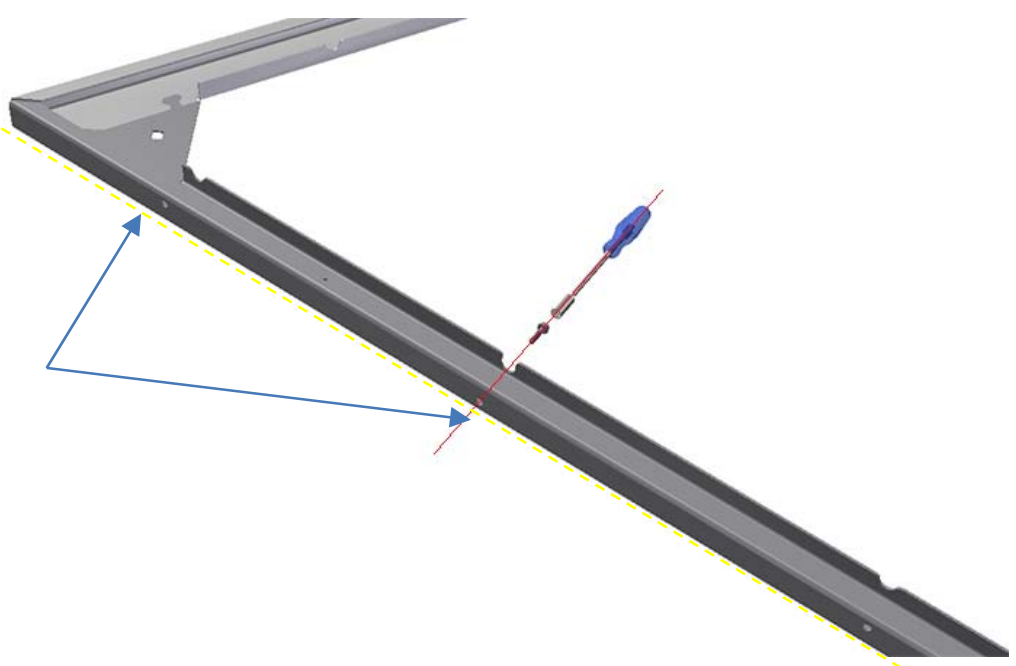

Fonte: Acervo pessoal dos autores, 2015.

\section{CONSIDERAÇÕES FINAIS}

O uso dos softwares de projeto de manufatura e de produção digital, aliado à gestão da informação no processo de projeto, viabilizou a produção de uma estrutura espacial que permitiu criar um ambiente habitável e aderente ao programa de necessidades, edificado uma única vez, com o elevado grau de precisão dimensional necessário para a execução de uma superfície com dupla curvatura, em prazos exíguos e por valores acessíveis.

A segurança proporcionada pela interoperabilidade permite a produção por processos semelhantes aos da indústria de produção seriada. Um sistema de gerenciamento similar ao das montadoras automobilísticas - que têm o domínio do projeto e terceirizam a produção de componentes, mantendo para si a responsabilidade pela montagem e pelo produto final permite a produção de objetos únicos, com baixo custo de investimento em infraestrutura. 
À semelhança do que foi apresentado neste artigo, o emprego dos métodos de modelagem e prototipagem digital tem potencial de alterar a atuação do arquiteto no processo de projeto, ampliando a sua influência no domínio da fabricação e montagem de estruturas. Os resultados obtidos neste trabalho também contribuem para o repertório de soluções de projeto e produção de estruturas geodésicas deste porte; soluções que podem ser parcialmente generalizadas para outras estruturas não convencionais.

\section{AGRADECIMENTOS}

Ao Sergio Silva de Freitas, Presidente do Conselho, e Ricardo Pisanelli, Gerente de Conteúdo do Catavento Cultural e Educacional pelas informações prestadas e pelo apoio à pesquisa.

\section{REFERÊNCIAS}

ASSOCIAÇÃO BRASILEIRA DE NORMAS TÉCNICAS. NBR NM 87: Aço carbono e ligados para construção mecânica - Designação e composição química. Rio de Janeiro, 2000.

BERNSTEIN, Phillip G.; PITTMAN, Jon H. Barriers to the Adoption of Building Information Modeling in the Building Industry. AUTODESK BUILDING SOLUTIONS. White Paper. Audesk, Inc. November 2004. Avaiable at <http://academics.triton.edu/faculty/fheitzman/Barriers $\% 20$ to $\% 20$ the $\%$ 20Adoption\%20of\%20BIM\%20in\%20the\%20Building\%20Industry.pdf>. Access Feb 2nd 2015

CARVALHO, Kleber Santos. Pavilhões e centros de exposição em São Paulo: cidadelas modernas do mundo globalizado. 2009. 194 f. Dissertação (Mestrado em Arquitetura e Urbanismo) - Faculdade de Arquitetura e Urbanismo, Universidade de São Paulo. São Paulo, 2009.

EDEMSKAYA, Elizaveta D. Rethinking complexity: steel lattice structures, past and present. Dissertation (Master of Architecture) - School of Architecture, University of Liverpool, 2014.

ESCOLA SENAI SUIÇO-BRASILEIRA. Métodos e processos de usinagem de precisão. São Paulo, 2005.

KÜHL, Beatriz Mugayar. Notas sobre a Carta de Veneza. An mus paul, São Paulo, v. 18, n. 2, p. 287-320, Dez. 2010.

LOTUFO, Vitor Amaral; LOPES, João Marcos de Almeida. Geodésicas \& Cia. $1^{\text {a }}$ ed. São Paulo: Projeto Editores Associados Ltda., 1981. 60 p.

SÃO PAULO (Estado). Secretaria de Estado da Cultura. Grupo de Projetos e Obras. Termo de Referência. Contratação de Empresa Especializada para Elaboração de Projeto Executivo de Instalações Elétricas no Palácio das Indústrias - Catavento Cultural e Educacional. 2013.

STEEL CONSTRUCTION INSTIUTUTE. Design for construction. SCI Publication 178. Ascot: Steel Construction Institute. 1997. 135 p.

VENDRAME, Adriano Márcio. Contribuição ao estudo das cúpulas treliçadas utilizando elementos tubulares em aço. 1999. 139 f. Dissertação (Mestrado em Engenharia de Estruturas) Escola de Engenharia de São Carlos. Universidade de São Paulo. São Carlos.

YOUNG JR, N. W.; JONES, S. A.; BERNSTEIN, H. M. Interoperability in the construction industry. SmartMarket Report: design \& construction intelligence. McGraw Hill Construction. 2007. Disponível em <http://www.aia.org/aiaucmp/groups/aia/documents/pdf/aias077485.pdf>. Acessado em 01/Junho/2015. 